\title{
LIMITES DO CONSEQUENCIALISMO NO DIREITO: DOS DILEMAS TROLLEY AO CORONAVÍRUS
}

RESUMO: Nestes tempos de crise provocada pelo Coronavírus, tem se popularizado a ideia de que o direito deve ceder a argumentos consequencialistas. Neste breve ensaio, pretendo levantar questionamentos sobre esse consequencialismo jurídico, mostrando seus problemas, frequentemente negligenciados por seus defensores. Critico a importação de discussões puras de filosofia moral para o direito, como a disputa entre utilitarismo e deontologia ilustrada pelos dilemas trolley. Os raciocínios jurídicos operam sob outra lógica, de concretizar direitos já existentes. Demonstro como uma criteriologia jurídica, apesar de ter sido constituída sob elementos de moralidade política, não se confunde com juízos morais para a solução de casos. Para tanto, ofereço uma série de exemplos que mostram o caráter distinto que uma teoria da decisão assume no direito. Por fim, analiso dois casos judiciais extremos no enfrentamento da pandemia, em que se decidiu de modo consequencialista ou formalista, e defendo uma terceira via, na linha de Ronald Dworkin: as decisões por princípio.

PAlavras-Chave: consequencialismo; filosofia moral; teoria da decisão; pandemia.

\footnotetext{
${ }^{1}$ Doutor em Direito (UFSC). Pós-Doutor em Direito (FDUL). Professor titular da Unisinos - RS e Unesa - RJ. Procurador de justiça aposentado do RS. Advogado e parecerista.
} 
ABSTRACT: In these times of crisis caused by the Coronavirus, the idea that the law must yield to consequentialist arguments has become popular. In this brief essay, I intend to raise questions about this legal consequentialism, showing its problems, often overlooked by its defenders. I criticize the importation of discussions from moral philosophy into law, such as the dispute between utilitarianism and deontology illustrated by the trolley dilemmas. Legal reasoning operates under another logic, to implement existing rights. I demonstrate as a legal criteriology, despite having been constituted under elements of political morality, it is not to be confused with moral judgments for the solution of cases. To this end, I offer a series of examples that show the distinct character that a theory of decision assumes in law. Finally, I analyze two extreme judicial cases in the face of the pandemic, in which it was decided in a consequentialist or formalistic way, and I defend a third way, in line with Ronald Dworkin: decisions based on principle.

KEYWORDS: consequentialism; moral philosophy; decision theory; pandemic.

\section{INTRODUÇÃO}

Nestes tempos de crise provocada pelo Coronavírus, tem se popularizado a ideia de que o direito deve ceder a argumentos consequencialistas. Neste breve ensaio, pretendo levantar questionamentos sobre esse consequencialismo jurídico, mostrando seus problemas, frequentemente negligenciados por seus defensores.

Como se tem colocado, o consequencialismo seria uma postura pela qual o valor de uma ação é dado pelos resultados que produz e não por princípios deontológicos. Seria aquilo que Dworkin (2010) chamaria de decisão por política e não por princípio.

Os consequencialistas brasileiros também admitiriam hierarquia entre pessoas. Dizem, por exemplo, que deveríamos afrouxar as regras da quarentena e reabrir o comércio porque a economia não pode parar. Alguns empresários chegam a dizer que "afinal, morreriam apenas pessoas mais velhas", mas que isso seria um mal necessário.

Nesse sentido, é de estranhar a baixa reação da comunidade jurídica àquilo que podemos denominar de "eugenia à brasileira". Com efeito, vários Conselhos Regionais de Medicina elaboraram protocolos ara "escolhas trágicas" durante a pandemia. Ainda que adotando critérios em parte específicos, os procedimentos elencados valem-se, dentre outros, da funcionalidade para eleger determinados pacientes pressupondo que eles possuem melhores chances de responder ao tratamento intensivo e maiores expectativas de sobrevida. Parece assustador, pois não? A estratificação de acordo com a gravidade de determinadas disfunções orgânicas, ainda que transitórias, parte do pressuposto de que elas permitem aferir a sobrevivência a curto prazo, bem como selecionar aqueles que possuem maior probabilidade de recuperação da infecção por Covid-19. Entretanto, estudos científicos realizados quanto à utilização do Sequential Organ Failure 
Assessment durante pandemia decorrente do vírus H1N1 no ano 2009 constataram que o critério se mostrou inadequado para priorizar o acesso às UTIs, uma vez que a mortalidade aferida posteriormente não refletiu as estimativas prévias (Michael D. Christian e outros. Care of the critically ill and injured during pandemics and disasters. Chest Journal, 2014). Ainda que os modelos elaborados no Brasil atualmente considerem outras variáveis, as quais vão além das disfunções orgânicas, não há evidências científicas conclusivas quanto à eficácia dos scores. Outro ponto de discussão é que referido critério - ao incorporar, exemplificativamente, índices relativos à pressão arterial, dopamina, dobutamina, noraeponefrina, creatina e diurese - gera desvantagem para as gestantes, as quais desenvolvem alterações significativas em tais aspectos Guardadas as devidas proporções, os citados critérios de priorização fazem repercutir - com alguma sofisticação e obnubilação - superadas teorias sociais darwinianas por meio das quais a utilidade à sociedade é um critério para determinação do valor humano (STRECK; SERRANO; CATTONI; BARRETO LIMA, 2020).

Com esse uso vulgar do consequencialismo, costuma-se ignorar alguns problemas filosóficos. O primeiro deles é: quais os critérios que se está assumindo para dizer que uma consequência é boa? Alguma teoria nesse sentido precisa ser apresentada.

No direito, o problema é ainda maior. É preciso reconhecer que os critérios avaliativos de uma decisão jurídica já existem e foram produzidos democraticamente, pelo processo legislativo. Portanto, não se pode transacionar livremente entre eles. Isso deveria ser algo básico, mas costuma ser deixado de lado. E muda todo o enquadramento da discussão.

\section{Porque JURistas NÃo DeVERIAM TRATAR DE "Dilemas TROLleY"}

Em muitos cursos de graduação e pós estão discutindo os dilemas morais que levanta o professor de Harvard, Michael Sandel (2015), como se isso fosse uma discussão de e sobre o direito. Os exemplos apresentados por Sandel tais como o "trolley dilemma" (Dilema do Vagão) servem como pontos de partida para a problematização acerca dos sistemas éticos. Ou seja, tem uma finalidade didática e uma abordagem específica. Infelizmente, a partir desses exemplos, já começam as importações acríticas para o direito. E, com elas, o sacrifício da autonomia desta área.

O dilema mais famoso discutido por Sandel diz: você está em um trem que tem pela frente cinco pessoas... mas tem um desvio que pode ser feito, onde está um só pessoa... O que você faz? Desvia o trem, matando uma pessoa para salvar as outras cinco?

Minha questão é mais básica: o que isso tem a ver (diretamente) com o Direito? Serve, sim, para discutir filosofia moral; mas, para o direito, uma aplicação direta só fragiliza sua autonomia. 
Permitam aqui desfazer qualquer tipo de mal-entendido: sei que Sandel é um jusfilósofo dos bons. Nada tenho contra o seu célebre curso Justice, no qual trata, em linguagem direta, desanuviada e sem imposturas, do pensamento de gente como Aristóteles, Kant, Bentham e Rawls. É uma prova, aliás, de que clareza e simplificação não são sinônimos. Também, endosso sua postura de tentar resgatar o debate público, em especial o político, das trevas onde se encontra hoje em dia. Ao demonstrar que problemas morais têm repercussão no âmbito político (na construção de uma sociedade justa etc.), Sandel acerta.

Aliás, também Dworkin - fazendo aqui um brevíssimo "parênteses" - é um autor identificado com essa postura: a de participar ativamente do debate público, tentando ultrapassar a barreira entre a linguagem profissional, acadêmica, e as questões que ocupam a ordem do dia. O seu Is Democracy Possible Here? (2006) é um dos muitos bons exemplos disso. Neste ensaio, Dworkin propõe que se faça uma espécie de depuração do debate político norte-americano, polarizado entre Democratas e Republicanos. Dworkin procura estabelecer um common ground entre adversários políticos (e não inimigos) que torne a discussão autêntica e produtiva. Concordamos que valores como dignidade, igualdade e democracia são importantes (ainda que discordemos a respeito do que estes conceitos significam)? Eis aí um bom ponto de partida.

Retomando, considero que as lições de Sandel, se bem lidas, fazem (muito) mais bem do que mal ao debate público e, mesmo, à argumentação jurídica. Mas seus exemplos devem ser lidos com uma advertência: "você, que escolhe se mata ou não uma pessoa, não está agindo como um jurista". O agente moral que deve fazer esta escolha não representa um juiz em sua tomada de decisão enquanto agente público. Desenvolvo isso ad nauseam em Jurisdição Constitucional e Decisão Jurídica (2014) e no Dicionário de Hermenêutica (2020).

Voltemos ao dilema trolley e à eventual moralidade do assassinato. Sandel utiliza esse problema para ilustrar as posturas utilitaristas. A morte de uma pessoa seria preferível à morte de cinco. Contudo, a audiência recua diante da hipótese de terem de jogar contra o trem uma pessoa que estava fora dos trilhos para salvar outras cinco. A maioria fica desconfortável em assumir a responsabilidade por matar deliberadamente uma pessoa que nada tinha a ver com o problema; e isso leva a reformular, ou a refinar, o argumento inicial de que a vida de muitos vale mais do que a vida de um só. Não precisamos ir muito longe para sermos apresentados a uma versão preliminar do conceito de dignidade humana, pela qual a vida humana tem uma dimensão não instrumental.

Ocorre que um jurista não está em condições de fazer este tipo de escolha fundamental (entre o utilitarismo e a dignidade, por exemplo). Para ser bem claro sobre esse ponto: já há um sistema (de regras, princípios etc.) que lhe antecede e que lhe coloca em condições de dizer algo. Ninguém quer saber se o juiz do caso é consequencialista. O direito democrático não pode depender disso. 
Você tem ou não tem um direito? Essa resposta depende de uma argumentação jurídica, e o juiz tem a reponsabilidade de desenvolvê-la de forma adequada, a partir do material jurídico existente.

De maneira didática, posso ilustrar os limites que o direito coloca ao consequencialismo. E o faço por meio de uma série de TV, House of Cards. O médico de House of Cards, quando, instado a que deixasse o presidente americano baleado fazer transplante de fígado, disse que não poderia "furar a fila": It's the law. O princípio é: uma vida é igual a uma vida. Não importa de quem seja a vida. Não há hierarquia de vidas. Comércio e indústria? Empregos? Resposta: uma vida é igual a uma vida!

Por isso, de uma perspectiva jurídica, não é possível admitir especulações consequencialistas para relativizar direitos fundamentais. Não se pode admitir uma argumentação que defendesse sacrificar vidas para salvar a economia.

Vale registrar que, no caso do enfrentamento da pandemia, essa linha de argumentação não pode ser sustentada, não apenas por sua impossibilidade jurídica ou sua indignidade moral, como também pelas próprias consequências econômicas negativas que geraria. Uma sobrecarga no SUS - para ficar apenas nisto - é ruim também para economia, para aqueles que adoram fazer cálculos com a vida alheia.

Ao que tudo indica, o dilema consequencialista que tem sido colocado no debate público brasileiro, entre saúde e economia no enfrentamento da pandemia, é apenas uma narrativa política para aumentar polarizações, sem base jurídica, filosófica e nem mesmo econômica.

\section{OS CRITÉRIOS PRÓPRIOS DO DIREITO}

Um dos assuntos sobre os quais sou frequentemente questionado é a diferenciação que estabeleço entre decisão e escolha. Tento explicar essa minha tese, advinda da imbricação que faço da hermenêutica filosófica com a teoria integrativa de Dworkin. Diante de um caso, um juiz não pode simplesmente escolher entre soluções alternativas. Ele tem a responsabilidade de buscar a solução superior às demais, que se imponha como a correta compreensão do direito.

Muitos me indagam se isso não me transforma em um positivista exegético. Respondo que não, porque não defendo qualquer espécie de literalismo/textualismo/formalismo. Defendo apenas que existem verdades na interpretação, que podem ser controladas pela comunidade de intérpretes.

É importante colocar essa defesa em um contexto, diferente do velho exegetismo. Um dos pontos que sempre deixo claro é que o direito, no segundo pós-guerra, assume um novo paradigma. A Constituição virou norma. Observe-se que nos EUA, bem antes disso, é pertinente observar que a Constituição não sofreu qualquer influxo direto do pós-guerra; na realidade, o pós-guerra da Europa Continental é o pós-guerra civil dos americanos (sempre é bom diferenciar estas tradições, até porque, por aqui, trabalhamos com ambas). 
O direito havia fracassado com as duas grandes guerras: genocídios e todos os tipos de tragédias nas e pelas quais o direito nada pode fazer ou resolver. Eis que, transformadas as constituições em norma, o direito assume uma faceta de transformação social. O ideal de vida boa é transportado para "dentro" dos textos. O velho positivismo, que havia cindido direito e moral, agora é (ou deveria ter sido) suplantado por teses como a cooriginariedade entre direito e moral ${ }^{2}$ (HABERMAS, 1997).

Embora a moral esteja presente no processo de formação do direito, ela não pode ser invocada em sua forma pura no momento da decisão judicial para corrigilo, reabrindo o processo legislativo e o pacto constitucional.

É claro que, dada a cooriginariedade entre Direito e Moral (e o fato de o comando jurídico não poder contrariar o conteúdo moral, apesar de com este não se confundir), o argumento jurídico é, na sua raiz, moral. Por isso Dworkin (2014) irá ainda mais longe e dirá que o Direito é um ramo da Moral. Mas a moralidade que o jurista articula quando argumenta não é a sua moralidade privada; não é a mesma que governa suas escolhas pessoais. A moralidade pública e política é outra, e gira, em Estados Democráticos ao menos, em torno de um sistema de direitos. Você tem ou não tem um direito? Essa resposta depende de uma argumentação de princípios, e o juiz tem a reponsabilidade de desenvolvê-la de forma adequada. Não depende de uma escolha.

Tenho tentado mostrar esse grau de autonomia do direito (STRECK, 2020). Ele não pode ser corrigido por subjetivismos, seja com que roupagem for. Nessa linha, tenho utilizado algumas ilustrações. Confesso, ilustrações duras e até antipáticas. Mas bastante didáticas e isto ninguém pode negar!

Um aluno de medicina ou biologia alega objeção de consciência para não frequentar a cadeira de anatomia, onde são feitos exercícios com animais (dissecação). Entra em juízo e pede que a Universidade lhe proporcione um curriculum alternativo. O judiciário concede a ordem. Qual é o problema dessa decisão? Sem dúvida, a decisão é equivocada. Sem discutir o direito dos animais (essa é outra questão), não parece constitucional que o restante da sociedade transfira recursos para proporcionar o bem-estar da consciência moral do estudante. $\mathrm{O}$ juiz terá que responder a algumas perguntas, como: há um direito fundamental a cursar medicina? Se não há, o pleito não vinga. Segundo: a conduta é universalizável? Um estudante de direito pode alegar problemas morais e não cursar direito penal, por exemplo? E na engenharia, pode o estudante exigir um currículo próprio? E a isonomia, a igualdade, a república, etc. onde ficam? E os recursos, que são de todos, podem ser desviados em favor de um?

Pais que professam religião que proíbe transfusão de sangue levam seu filho ao hospital. O menino está com a vida em risco. Estado grave. Os médicos prescrevem

\footnotetext{
2 De novo, uma observação necessária: a discussão norte-americana se dá quase que paralelamente a isso; por lá, o positivismo jurídico ainda ocupa o mainstream, sem essa ênfase toda no anti (ou pós) positivismo.
} 
operação com transfusão de sangue. Indagam aos pais que vedam o procedimento. A criança morre. Os pais podem ser processados por homicídio? Inspiro-me aqui em caso real. Em situação do tipo, o Superior Tribunal de Justiça entendeu que os pais não deveriam ir a júri, porque agiram sem dolo eventual. Qual é o busílis? Os pais têm direito a assim proceder? Vejamos. Não devemos misturar moral com direito e nem religião com direito e tampouco religião com medicina. Os médicos não deveriam ter consultado os pais. Os pais não possuem o direito fundamental a que seu filho não faça transfusão de sangue. Seu direito de crença não vai ao ponto de sacrificar uma vida. Se dermos o direito aos pais de veto a um procedimento imprescindível prescrito por médicos entendidos no assunto, também teremos que aceitar que algum órgão público (MP ou Defensoria) ingresse com ação de danos morais contra o hospital que salvou o filho de um casal religioso. Afinal, poder-seia alegar que, ao salvar-lhes o filho, o hospital constituiu um dano moral na vida dos que professam a crença, porque sangue impuro estaria circulando nas veias do paciente (ou algum argumento desse jaez). Exageros meus à parte, nesse sentido o STJ acertou, embora não tenha desenvolvido à saciedade uma argumentação que possa servir para casos futuros. Não basta dizer que não há dolo eventual. Há que fixar doutrina para casos futuros. O direito deve superar a moral e as crenças pessoais em uma coletividade.

Mutatis mutandis, isso se aplica aos casos de pessoas que exigem, judicialmente, que um concurso público seja feito em outro dia que não aquele em que a religião do utente permita trabalhar ou exercer atividades. Ora, não parece que exista um direito fundamental a que o utente faça aquele concurso específico. Por que os demais concidadãos devem transferir recursos para proporcionar o bem-estar de consciência de um indivíduo, isoladamente? Eu e você temos o direito de crer (ou não) no que quisermos: posso acreditar que se engolir três pescoços de galos-índio por dia vou purificar minha alma e assegurar meu lugar aos céus. Mas isso não me dá o direito, caso eu não tenha condições financeiras, de pleitear judicialmente ao Estado que me forneça um caminhão de pescoços sempre que necessitar. Exageros (de novo) à parte, fazer escolhas religiosas implica ônus. Muitos. Mesmo que a Constituição garanta a liberdade de credo, isto não quer dizer que tal direito se converta em direito subjetivo a obter aquilo que acredito para todas as hipóteses.

Há hoje o "imaginário Sandel", presente na doutrina das chamadas "escolhas trágicas" (sic) que o juiz seria levado a tomar, como se os dilemas morais apresentados fossem os casos difíceis do direito. Nesta linha dizem, equivocadamente: "quem deve morrer para que a decisão judicial em que se determina o fornecimento de leito a X seja cumprida".

De todo modo, o ponto é: a impossibilidade de transplantar a filosofia moral, sem mediação, para o Direito - coisa que acontece com quem trabalha com o paradigma das tais "escolhas trágicas", por exemplo. No âmbito judicial, não se está discutindo concepções abstratas do que seria a justiça. Se está julgando um caso concreto a partir do direito existente. 


\section{ANÁlise de CASOS: ENTRE O CONSEQUENCIALISMO E O FORMALISMO DIANTE DO CORONAVÍRUS}

Feitas essas reflexões teóricas, passo a analisar dois casos extremos surgidos no enfrentamento ao coronavírus, que ilustram os problemas discutidos até aqui.

O primeiro caso vem do Recife (ANGELO, 2020). Um juiz federal autorizou que um quase-advogado ou estagiário-advogado exercesse a profissão de advogado. Mesmo sem OAB, cuja segunda fase do exame foi adiada por conta da pandemia. Ele concedeu medida provisória de urgência. Pior: o pedido vem assinado pelo autor mesmo, não advogado. Baseado em quê? Quem vai saber. Talvez num consequencialismo jurídico, pelo qual essa relativização dos requisitos para exercício da advocacia lhe pareça compensar, numa análise de custo-benefício. Sozinho, um juiz se sentiu confortável para inventar uma solução ad hoc para um problema social altamente complexo, que deveria passar pelo respectivo conselho profissional e demais órgãos competentes. Isso pode ser universalizado para todos os outros estudantes de direito? E estudantes de outras áreas, poderão exercer suas profissões sem cumprir os requisitos necessários? É possível tratar esses casos como problemas meramente instrumentais, ou eles envolvem uma questão de princípio?

O segundo caso vem do Rio de Janeiro. Vejam a manchete: "Justiça do Rio nega pedido para suspender cultos de Silas Malafaia por coronavírus" (RODAS, 2020). O juiz que prolatou a decisão afirmou que o princípio da legalidade estabelece que "ninguém será obrigado a fazer ou deixar de fazer alguma coisa senão em virtude de lei". Como não há decreto do Executivo ou lei do Legislativo afastando, por ora, o direito à participação em cultos religiosos, não cabe ao Judiciário, diz o juiz, "fazer integrações pelo método analógico, quando não há lacuna na norma".

Com essa interpretação estreita, o juiz esqueceu-se do resto do ordenamento jurídico, e dos demais direitos e deveres em jogo. Isso não é legalidade. É legalismo. Ou textualismo-retrô. E explico a razão disso: legalidade é algo que envolve todos os fundamentos que dão sentido à prática do Direito. Dworkin dirá que a interpretação correta, adequada, em Direito é aquela que justifica a prática colocando-a sob sua melhor luz. Será que se apegar a uma frágil ideia de legalidade, já ultrapassada no final do século XIX, é colocar o Direito sob sua melhor luz?

Será mesmo que ainda estamos na época do dualismo, racionalístico-positivista, de que Direito é uma coisa, princípios são outra, Direito não responde tudo, juiz ou é ativista ou se cala? Ora, deveria ser evidente que a resposta para isso é não. $O$ problema é que a práxis brasileira, dogmática, dogmatizada e dogmatista, insiste nesses dualismos. Insiste nessa tese de que não há legalidade fora da "letra fria" (sic) da lei. Ou, no contraponto, tudo é remetido ao realismo jurídico, pelo qual “o Direito é o que os tribunais dizem que é".

A decisão do juiz de direito do Rio de Janeiro parece repetir o velho exemplo da Teoria do Direito: diante da regra "Proibido cães na plataforma", proíbe-se o cãoguia do cego. E autoriza o livre trânsito de ursos. E jacarés. Tigres. O mais estranho 
é que sua decisão se deu "obedecendo ao Direito", o que apenas demonstra o acerto da tese de que há uma falsa dicotomia entre literalismo (ou textualismo) e voluntarismo (STRECK, 2020), (verbetes Literalidade e Voluntarismo).

Como se o Direito não fosse todo um conjunto a ser interpretado como um todo coerente. Vive-se, nas práticas cotidianas, uma espécie de "dicotomia textualismovoluntarismo" ad hoc. O Judiciário não faz nada enquanto não houver, letrinha por letrinha, uma ordem, até que o juiz não queira assim. De um lado, a subsunção (ou o que dela se diz); de outro, quando for conveniente, um "livre atribuir de sentidos". É uma espécie de "deontologia consequencialista". O mesmo juiz legalista, quando lhe interessa, pode julgar de forma voluntarista.

No clássico caso Riggs v. Palmer, em que o neto matou o avô para ficar com a herança, nossa complacência doutrinária entenderia - nítida na decisão sob comento - que, não havendo regra expressa-literal, o neto assassino que herde. Não pode ser assim. E assim não foi. Porque o Direito diz que não é assim.

O Direito não é só um conjunto de regras. É uma questão de princípio. Autêntico. O problema? Não houve, até hoje, uma adequada compreensão ou mesmo recepção de uma adequada teoria dos princípios, que exigisse um ajuste institucional por parte do intérprete que invoca um padrão principiológico. Claro: estamos ainda no tempo em que legalidade é "aplicar a letra da lei". Porque não temos um rigor epistemológico. Nesse sentido, não surpreende que ainda parcela majoritária da doutrina ensine que "princípios são valores", sem que se especifique de que "valores" se trata. Como explico no verbete Valores (STRECK, 2020), ainda que se diga que valores são objetivos e universais, princípios (jurídicos) não são valores. Porque, ainda que valores sejam universais, falar em valores pressupõe o pluralismo valorativo; e o pluralismo pressupõe o conflito. Se princípios são valores, é o intérprete-juiz que escolhe o valor aplicável. E isso não cabe em uma democracia. Aquilo que viria de "fora" para possibilitar que o intérprete pudesse "ir além da lei ou do Direito" - visto como "Direito posto" -, transforma-se, na verdade, em um subjetivismo sem medida. Por isso a proliferação daquilo que denominei, de há muito, de pamprincipiologismo.

Vejam-se as duas pontas do Direito brasileiro. No RJ, um juiz se apega a um legalismo. No Recife, um juiz decide francamente contra legem. Tudo no mesmo dia. Afinal, o grande problema que atravessa tudo isso é o desprezo por uma criteriologia jurídica nas tomadas de decisão. Ora os juízes ficam aquém do que ela exige, ao se dizerem literalistas; ora vão muito além do que ela autoriza, ao inventarem direitos com base em juízos morais puros e análises consequenciais. Pior: como se a teoria do Direito se dividisse entre literalistas (ou textualistas) e voluntaristas, nas duas diversas formas. Ou entre textualismo e pragmatismo, conforme a clássica crítica de Dworkin, para introduzir a sua teoria integrativa.

\section{CONSIDERAÇÕES FINAIS}


A pandemia que se está enfrentando agravou problemas antigos do Direito brasileiro. Dentre eles, se destaca a falta de critérios públicos universalizáveis em nossas decisões judiciais. Sequer se percebe, nas práticas cotidianas, a distinção entre ativismo e judicialização.

Nesse sentido, tem se popularizado um imaginário consequencialista, para relativizar direitos estabelecidos, sob uma retórica da crise. Com isso, se desconsidera: a existência de meios jurídicos que já são capazes de resolver várias dessas questões; a necessidade de se remeter escolhas fundamentais para as arenas políticas apropriadas; a falta até mesmo de coerência interna nesse consequencialismo brasileiro, que não considera seriamente as consequências dos sacrifícios que defende, criando falsos dilemas entre saúde e economia.

O Direito deve chegar antes. Trata-se de uma questão de princípio. O Direito não lida e não resolve dilemas morais (STRECK, 2020). Se chegar a esse ponto, é porque fracassou. E fracassou também o processo civilizatório.

É nesse sentido que, neste breve ensaio, critiquei a importação de discussões puras de filosofia moral para o direito, como a disputa entre utilitarismo e deontologia ilustrada pelos dilemas trolley. Os raciocínios jurídicos operam sob outra lógica, de concretizar direitos já existentes. Juristas trabalham com um material jurídico básico - Constituição, leis, regulamentos, precedentes, doutrinas - que foi democraticamente produzido. Essa é a base de uma criteriologia própria do Direito.

Na sequência, demonstrei como essa criteriologia jurídica, apesar de ter sido constituída sob elementos de moralidade política, não se confunde com juízos morais para a solução de casos. Ofereci uma série de exemplos que mostram o caráter distinto que uma teoria da decisão assume no Direito.

Por fim, analisei dois casos judiciais extremos no enfrentamento da pandemia, em que se decidiu de modo consequencialista ou formalista. Isso me possibilita esclarecer um ponto, na mesma linha de Dworkin: ao criticar decisões judiciais baseadas em argumentos de política, não estou dizendo que bastam regras, literalismos e uma coerência formal com decisões anteriores. Esse tipo de postura pode levar a absurdos que ferem a integridade do Direito - permitindo cultos em cenários de pandemia. E preciso buscar uma consistência de princípio nas decisões, à luz de todo o Direito. O mesmo princípio que valeu para o caso de um cidadão deve valer para os demais, a não ser que as condições interpretativas exijam que prevaleça um outro princípio. Essa é a racionalidade jurídica que devemos buscar, e que se torna urgente em tempos de crise.

\section{REFERÊNCIAS}

STRECK, Lênio Luiz. Dicionário de hermenêutica: cinquenta temas fundamentais da Teoria do Direito a luz da Crítica Hermenêutica do Direito. 2. ed. Belo Horizonte: Casa do Direito, 2020. 
DWORKIN, Ronald. Is Democracy Possible Here? Principles for a New Political Debate. Princeton: Princeton University Press, 2006.

DWORKIN, Ronald. Levando os direitos a sério. 3. ed. São Paulo: Martins Fontes, 2010.

ANGELO, Thiago. Revista Consultor Jurídico. São Paulo, 21 de março de 2020. Disponível em < https://www.conjur.com.br/2020-mar-21/bacharel-direitoadvogar-aprovacao-exame-oab>. Acesso em: 10 jun 2020.

DWORKIN, Ronald. A raposa e o porco-espinho: justiça e valor. São Paulo: WMF Martins Fontes, 2014.

HABERMAS, Jürgen. Direito e Democracia: entre facticidade e validade. Tradução de Flavio Beno Siebeneichler. Rio de Janeiro: Tempo Brasileiro, v. I e II, 1997.

RODAS, Sergio. Revista Consultor Jurídico, São Paulo, 20 de março de 2020. Disponível em:< https://www.conjur.com.br/2020-mar-20/justica-rio-nega-pedidosuspender-cultos-silas-malafaia>. Acesso em: 10 jun 2020.

SANDEL, Michael J. Justiça: o que é fazer a coisa certa. 19. ed. Rio de Janeiro: Civilização Brasileira, 2015.

STRECK, L.L.; SERRANO, P.; CATTONI, M.; BARRETO LIMA, M. Revista Consultor Jurídico, São Paulo, 1 de junho de 2020. Disponível em: $<$ https://www.conjur.com.br/2020-jun-01/opiniao-covid-19-eugenia-brasileira>. Acesso em: 10 jun 2020.

STRECK, Lenio Luiz. Jurisdição Constitucional e Decisão Jurídica. 4. ed. São Paulo: Revista dos Tribunais, 2014. 